\title{
A TERCEIRA MISSÃO DA UNIVERSIDADE. DESENVOLVIMENTO SOCIOECONÔMICO, INVESTIGAÇÃO, DESENVOLVIMENTO E INOVAÇÃO (IひD+I), FORMULAÇÃO E IMPLEMENTAÇÃO DE POLÍTICAS PÚBLICAS
}

\author{
Eduardo Moreira Dias ${ }^{1}$
}

RESUMO: Desde suas origens até a atualidade, a Universidade sempre foi confrontada com a necessidade de mudar. Os momentos históricos demonstram as relações de causalidade, especialmente no que refere às mudanças na concepção e ideologia dos Estados e ao conjunto de fatores socioeconômicos e políticos preponderantes para tais transformações. Por conseguinte, ao longo do tempo, as Universidades foram assumindo missões para além das atividades de ensino. Inicialmente foram incorporadas as atividades de pesquisa/investigação científica e mais tarde as atividades de extensão, os serviços à sociedade, o que veio a ser denominado como a Terceira Missão da Universidade. Este artigo aborda as principais questões pertinentes ao tema, em seções distintas, porém intercorrentes, e lança luz sobre uma temática transversal que envolve a sociedade, os governos, as instituições/organizações públicas e privadas, designadamente: Desenvolvimento socioeconômico; Educação; Investigação, Desenvolvimento e Inovação $(I \partial D+i)$; Formulação e Implementação de Políticas Públicas; Bem-estar social.

Palavras-chave: Universidade. Terceira Missão. Desenvolvimento Socioeconômico. Investigação. Desenvolvimento e Inovação $(I d D+i)$. Formulação e Implementação de Políticas Públicas. Bem-estar social.

\section{INTRODUÇÃO}

Desde suas origens até a atualidade, a Universidade sempre foi confrontada com a necessidade de mudar. Os momentos históricos demonstram as relações de causalidade, especialmente no que refere às mudanças na concepção e ideologia dos Estados e ao conjunto de fatores socioeconômicos e políticos preponderantes para tais transformações.

Por conseguinte, ao longo do tempo, as Universidades foram assumindo missões para além das atividades de ensino. No século XIX foram incorporadas as atividades de

\footnotetext{
${ }^{\mathrm{I}}$ Executivo de Gestão e Operações | Especialista em Gestão Educacional | Especialista em Gestão Comercial, Relacionamento $\mathrm{B}_{2} \mathrm{~B}_{2} \mathrm{C}$ e Comunicação Multicanal | Especialista em Políticas Públicas. ORCID: oooo-ooo33696-o815. E-mail: eduardo.moreira.dias@hotmail.com
} 
pesquisa/investigação científica e mais tarde as atividades de extensão, os serviços à sociedade, o que veio a ser denominado como a Terceira Missão da Universidade.

A partir dos anos de 1990 verifica-se um amplo movimento de reformas e de reestruturações das Instituições de Ensino Superior (IES), impulsionado por oportunidades mercadológicas ocasionadas pelo aumento da demanda por formações de nível superior. Paralelamente, ocorre o fenômeno expansionista e depois os movimentos de fusões e incorporações, com o surgimento de grandes grupos educacionais.

Atualmente, as IES estão a passar por um momento conturbado, de ameaças e incertezas, potenciado por diversas variáveis, sobretudo no âmbito macroeconômico, consequentes da pandemia de covid-ig.

Este artigo aborda as principais questões pertinentes ao tema através das lentes de investigadores e autores expoentes, em seções distintas, porém intercorrentes, apresenta resposta à pergunta a seguir exposta e lança luz sobre uma temática transversal que envolve a sociedade, os governos, as instituições/organizações públicas e privadas.

Enfim, as Instituições de Ensino Superior, no âmbito das atividades associadas à Terceira Missão, podem desempenhar papéis importantes no contexto dos governos regionais e, consequentemente, contribuir de forma inédita e inovadora para o crescimento e desenvolvimento socioeconômico dos territórios e na construção de políticas públicas?

\section{REFERENCIAL TEÓRICO}

\section{I. Os Desafios e as Perspectivas da Universidade - Uma Abordagem Sintética dos Momentos Históricos}

"Até meados do século XIX a Universidade ainda se comportava como numa torre de marfim, num "misto de claustro e de guilda medieval”, optou por isolar-se a integrar-se à sociedade. Seletiva, acolhia poucos alunos e orgulhava-se da qualidade dos seus "intelectuais e de seus eruditos". Até então, a sua missão era acautelar e transmitir o saber" (A. Teixeira, 1964), especificamente no âmbito das profissões de direito, medicina, teologia e disciplinas científicas (Altbach, 200I). Contudo, esse modelo isolacionista e elitista começou a transformar-se com o surgimento das três revoluções: a revolução científica, a revolução industrial e a revolução democrática (A. Teixeira, 1964). 
No final do século XVIII e início do século XIX surge a Universidade moderna, cujo advento está associado com as reformas de von Humboldt na Prússia e de Napoleão na França (Neave e van Vught, 1994, citado por Amaral \& Magalhães, 2003, p. 2). "Ao longo dos séculos seguintes, a Universidade floresceu como um verdadeiro centro de geração de alto conhecimento nas sociedades. Mas, para tal, ela teve de se reciclar, mudar e se adaptar, em diversos momentos, à realidade a seu redor" (Buarque, 2003, p. 29).

As crises de hegemonia, legitimidade e institucional apontadas por Boaventura de Sousa Santos (1994, 2004, 2008), pelas quais a Universidade foi confrontada ao longo dos tempos parecem não ter fim, sobretudo se considerarmos a confluência das suas especificidades no contexto contemporâneo. Como consequência, no decorrer da história a Universidade foi incorporando missões.

A integração da Universidade à sociedade e aos seus problemas, delineou-se pela inclusão da pesquisa/investigação científica na academia, nomeadamente a partir do aparecimento das novas Universidades alemãs no século XIX (A. Teixeira, 1964). Altbach assevera que no século XIX a pesquisa/investigação científica foi acrescentada às responsabilidades das Universidades e um pouco mais tarde o serviço à sociedade (200I). Boaventura de Sousa Santos (1994) acrescenta que "a centralidade da Universidade enquanto lugar privilegiado da produção de alta cultura e conhecimento científico avançado é um fenómeno do século XIX, do período do capitalismo liberal, e o modelo que melhor o traduz é o modelo alemão, a Universidade de Humboldt” (p. r68).

A partir dos anos de 1990 verifica-se um amplo movimento de reformas e de reestruturações dos sistemas de educação superior no sentido de melhor atender às novas necessidades das sociedades e ao aumento da demanda de formação superior. A concorrência e a política expansionista levaram à formação de grandes grupos educacionais. As IES começaram a investir na profissionalização dos seus quadros e fomentaram o emprego de conceitos de gestão empresarial, como, por exemplo, a criação de centros de serviços compartilhados, no âmbito da eficiência, e por outro lado, no âmbito da eficácia, incentivaram a captação de receitas próprias com origem em "vendas e prestações de serviços” (Mano \& Marques, 2012) que impulsionaram as ligações externas, sobretudo ao meio empresarial e à sociedade, e possibilitaram uma participação ativa na 
definição de regras, planos e ações estratégicas, essencialmente através de uma maior articulação com os governos e com os atores sociais.

A Universidade contemporânea está a enfrentar um momento intricado e a ser confrontada com fenômenos considerados os mais severos desde sempre, a saber:

- A globalização e as transformações tecnológicas, nomeadamente a utilização de novas tecnologias de informação e comunicação;

- A massificação e todas as suas implicações;

- A adoção do modelo de gestão empresarial com ênfase no desempenho e resultados;

- Uma profissão acadêmica cada vez mais internacional e móvel;

- O decréscimo das políticas de financiamento;

- As questões demográficas;

- Os ordenamentos jurídicos;

- O surgimento de redes globais de pesquisa/investigação científica;

- Os cenários macroeconômicos desfavoráveis, sobretudo derivados da pandemia de covid-r9.

Não obstante, os movimentos verificados no "mercado" educacional, sobretudo fusões e aquisições, que levaram ao surgimento de "gigantes do negócio mundial da educação", as expansões internacionais - mediante o estabelecimento de subsidiárias, controladas por instituições de renome internacional e o consequente reposicionamento das instituições de ensino superior no mercado educacional internacional (a internacionalização é um domínio de importância estratégica para as Universidades), a oferta de serviços educacionais "on-line" atingindo "clientes" em todas as partes do mundo são realidades que podem gerar implicações contundentes ao ensino superior, tendo em vista que a Universidade poderá ser definida de uma maneira inteiramente nova (Altbach, 200I).

Caraça et al. (1996) advertem a um provável resultado, que deve ser objeto de atenção e análise por parte das instituições, governos e sociedades:

No âmbito do ensino, emerge a necessidade de a Universidade se adaptar às novas exigências de qualificações do mercado de trabalho, desenvolvendo ações de formação profissional e de formação contínua.

Com as crescentes mutações tecnológicas, a exigência de qualificações profissionais mais complexas determina o envolvimento das Universidades, a par de outras instituições vocacionadas para o efeito, no esforço de proporcionarem oportunidades de formação profissional que se adequem aos requisitos da mudança tecnológica; 
As mutações tecnológicas introduzem outra consequência: a obsolescência da educação e da formação. Esta consequência exige a dedicação das Universidades para garantir padrões adequados de formação contínua, devidamente articulados com a educação inicial e interatuando com a investigação e as inovações tecnológicas. (p. 1229).

Por conseguinte, verifica-se um amplo movimento de reformas e de reestruturações dos sistemas de educação superior no sentido de melhor atender às novas necessidades das sociedades (Pedrosa, Santos, Mano, \& Gaspar, 2012) e, sobretudo, em consonância com a realidade de um tempo de ameaças e de incertezas, para assegurar a própria sobrevivência diante da concorrência.

Todavia, Buarque (2003) considera que "não é a primeira vez que a Universidade se vê confrontada com a necessidade de mudar, mas nunca ela precisou mudar tanto quanto agora" (p. 28).

\subsection{Inovação, Universidade e Relação com a Sociedade}

Nesse complexo e dinâmico novo mundo, a inovação está a ocupar função peremptória no contexto do desenvolvimento econômico (Śledzik, 2013). Historicamente, a Inovação e seu ciclo podem ser divididos em três etapas, a saber: invenção - existe desde o início da humanidade; imitação ou difusão - habitual nos mercados economicamente promovidos pela produção e terceirização de produtos de consumo e, por fim, a inovação (Santos, Faizon, \& Meroe, 201I).

Para Solo (195I) as mudanças tecnológicas compreendem o conjunto de transformações dos conhecimentos disponíveis, que podem ser denominadas invenções e, as mudanças reais nos arranjos tecnológicos, quando o conhecimento existente é aplicado, podem ser denominadas inovações.

"Como resultado dos rápidos avanços que estão sendo feitos em ciência e tecnologia, a inovação tornou-se um conceito-chave na sociedade de hoje" (Knight, 1967, p. 478). A inovação é um instrumento essencial dos empresários, um meio que se emprega para explorar a mudança e aproveitá-la como oportunidade para um negócio ser diferente, sendo possível, ainda, apresentá-la sob a égide de disciplina, aprendê-la e praticá-la (Drucker, 1989). Ainda segundo Drucker (1989), "uma empresa que não inova, envelhece e declina inevitavelmente" (p. 163). 
Nesse âmbito, conforme Santos, Fazion e Meroe (20II), a "inovação é estratégia para a sustentabilidade econômica das organizações no século XXI, emergente após a globalização da economia e alternativa para acompanhar a velocidade de demanda por novos produtos, característica da dinâmica contemporânea” (p. 2).

No contexto das organizações públicas, Lee (1970) afirma que "a inovação é o ponto crucial da reforma administrativa, ou seja, a injeção de novas ideias e novas pessoas em novas combinações de tarefas e relacionamentos no processo de política e administração. Este, entretanto, não é um processo automático. Ele exige estratégia, a fim de facilitar a sua adoção e difusão em toda a organização pública” (p. 177).

Nessa perspectiva, para Ven (1986) "a inovação é definida como o desenvolvimento e implementação de novas ideias por pessoas que, ao longo do tempo, comprometem-se em operações com outras pessoas dentro de um contexto institucional” (p. 59I).

De forma bastante interessante, Oliveira (1999) contextualiza o papel da inovação no âmbito sociológico. "O mundo não é constituído e movido unicamente por empresas e negócios com objetivos puramente imediatistas, mas também por uma realidade mais complexa, através da qual é comum que os negócios resultem da evolução sociocultural” (J. M. F. C. de Oliveira, 1999, p. 12).

"O efeito da inovação sobre o produto, a produtividade e o emprego é de particular interesse para as políticas de inovação, tanto no âmbito nacional como para setores específicos e regiões. Melhores informações sobre as condições de sucesso poderiam auxiliar o aperfeiçoamento de políticas que visam alcançar benefícios econômicos e sociais provenientes da inovação" (OECD, 1997, p. 52).

"O que chamamos de inovação não é o resultado de um indivíduo isolado, mas o produto de três forças, a saber:

\footnotetext{
Um conjunto de estruturas sociais (campo) que, de entre as variações produzidas por indivíduos, seleciona as que devem ser preservadas;

Um domínio cultural estável que preserva e transmite as ideias selecionadas às gerações seguintes;

O indivíduo que promove a mudança no domínio, que o campo aceita como inovadora.
}

A inovação é um fenômeno que resulta da interação destes três sistemas: sem um domínio culturalmente definido onde a criatividade é possível, o indivíduo nem pode 
começar; sem pares que avaliem e confirmem a adaptabilidade da inovação é impossível diferenciar o que é criativo do que é improvável, bizarro ou aberrante" (Csikszentmihalyi, 1988, citado por Oliveira, 1999, p. 14).

\section{Figura I - Modelo sociológico da inovação}

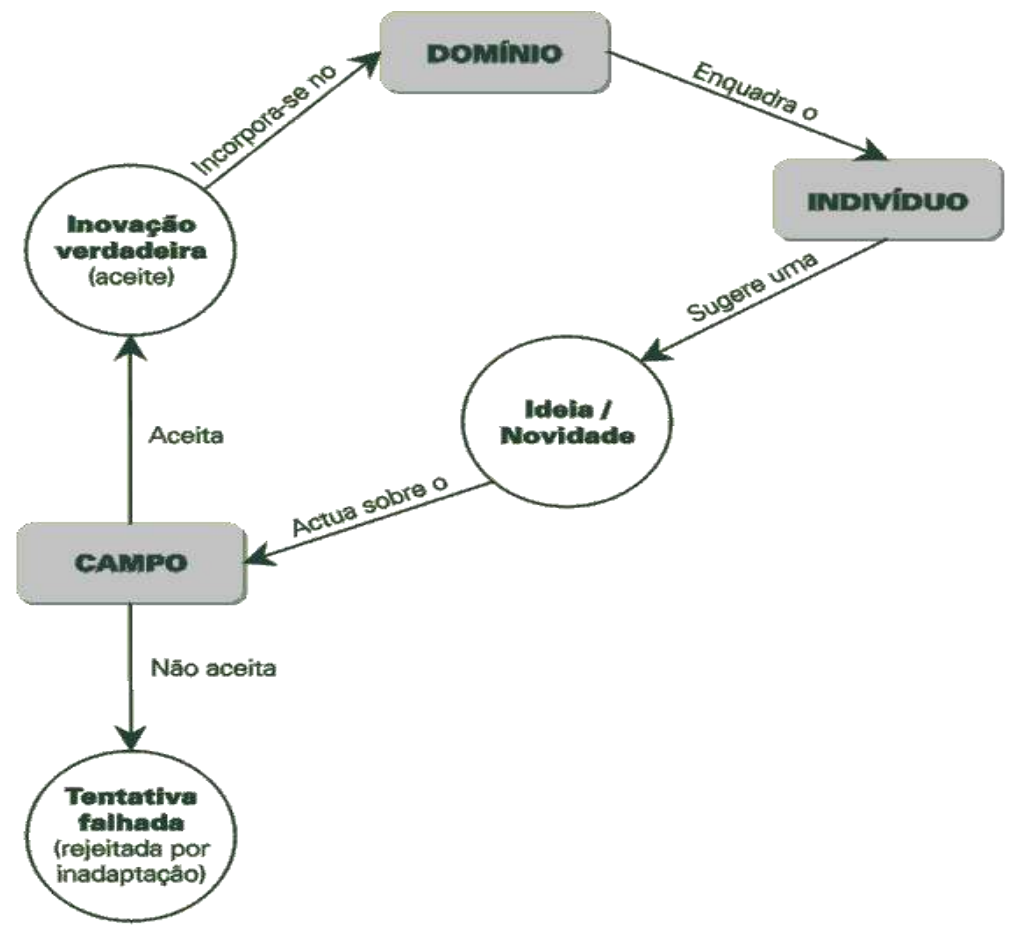

Fonte: (J. M. F. C. de Oliveira, 1999)

"Nesta definição, encontramos os elementos sociológicos básicos: o campo, o domínio e o indivíduo. A inovação bem sucedida (de entre todas as possíveis como resultado da criatividade) provoca uma mudança no domínio que é aceita e reconhecida pelo campo" (J. M. F. C. de Oliveira, 1999, p. 15). A “inovação é a transformação de ideias e/ou utilização de invenções, de que resultam aplicações úteis conducentes a melhoramentos" (J. M. F. C. de Oliveira, 1999, p. 12).

Conceitos como inovação, Universidade e relação com a sociedade ocupam as agendas de instituições internacionais como a OCDE e a UNESCO e são considerados determinantes para a Universidade do século XXI (Clotet, 2009).

"Entramos em um novo modo de criação de conhecimento onde existe uma ligação muito mais forte entre ciência e tecnologia e onde a inovação será tipicamente resultado da 
interação entre a multiplicidade de atores em muitas instituições e locais diferentes. Estes desenvolvimentos apontam para a necessidade de integrar a produção de conhecimento nas Universidades mais estreitamente com o processo de inovação" (Lundvall \& Borrás, I997, p. 157).

Por conseguinte, "a nova forma de pensar sobre a capacidade institucional centra-se sobre as teias de relações envolvidas nas políticas de desenvolvimento urbano, que interligam as agências públicas de desenvolvimento, empresas e institutos de ensino e pesquisa na ação coletiva, sendo assim a capacidade institucional é considerada como parte da capacidade combinatória" (Sotarauta, 2004, p. 43).

No âmbito da trilogia Universidade-Indústria-Governo, a formação de clusters impulsiona a inovação, promove a colaboração e gera eficiência. "A teoria dos clusters pressupõe papéis públicos que ainda são pouco compreendidos pelas empresas. Tópicos como geografia e localização devem ser observados como fundamentais na gestão. Há uma necessidade premente para reorientar o pensamento sobre estratégia de forma que a localização e a participação dos clusters sejam considerados para que os empreendimentos tenham sucesso" (Clrark, Feldman, \& Gertler, 200o, p. 278).

A região de Silicon Valley, na Califórnia, nos Estados Unidos, é um exemplo de cluster com concentração de um grande número de empresas de base tecnológica, sendo a Universidade de Stanford reconhecidamente a propulsora do seu surgimento.

Conforme Castells \& Himanen (2002), o Vale do Silício tem sido considerado como o modelo de inovação e de crescimento econômico que as sociedades devem observar para ter sucesso. No entanto, recentemente, o modelo finlandês, igualmente dinâmico em termos tecnológicos e econômicos ao Vale do Silício, mas que combina o sucesso tecnológico e econômico com justiça social e igualdade, o welfare state ou estado de bemestar social, está a atrair a atenção internacional (Castells \& Himanen, 2002). Um outro modelo é Singapura que apresenta um ambiente de inovação e desenvolvimento tecnológico considerável (Castells \& Himanen, 2002).

O desenvolvimento econômico, a formação de arranjos produtivos, a localização, o papel dos clusters e o seu relacionamento com a sociedade devem ser objeto de uma análise aprofundada, com identificação e avaliação de impactos regionais resultantes das 
principais transformações nas estruturas produtivas das regiões, incluindo-se aí as prováveis intercorrências das Instituições de Ensino Superior, que são importantes atores dos contextos de desenvolvimento territorial, regional e nacional. Elas promovem oportunidades de desenvolvimento econômico, sociocultural, e, sobretudo, educacional (Fernandes, 2009).

Consequentemente, amplia-se a perspectiva de relacionamento da Universidade para muito além da relação Universidade-Indústria-Governo, o chamado modelo Triple Helix, e do modelo Quadruple Helix, que inclui a sociedade no contexto de aplicação. No modelo Quintuple Helix, como observam Carayannis, Barth, \& Campbell (2012), as hélices influenciam-se mutuamente e desempenham funções decisivas.

Figura 2 - Modelo Estruturante e Translativo de Produção de Conhecimento e Inovação Baseado nos Contextos Sociais, Ambientais e Institucionais

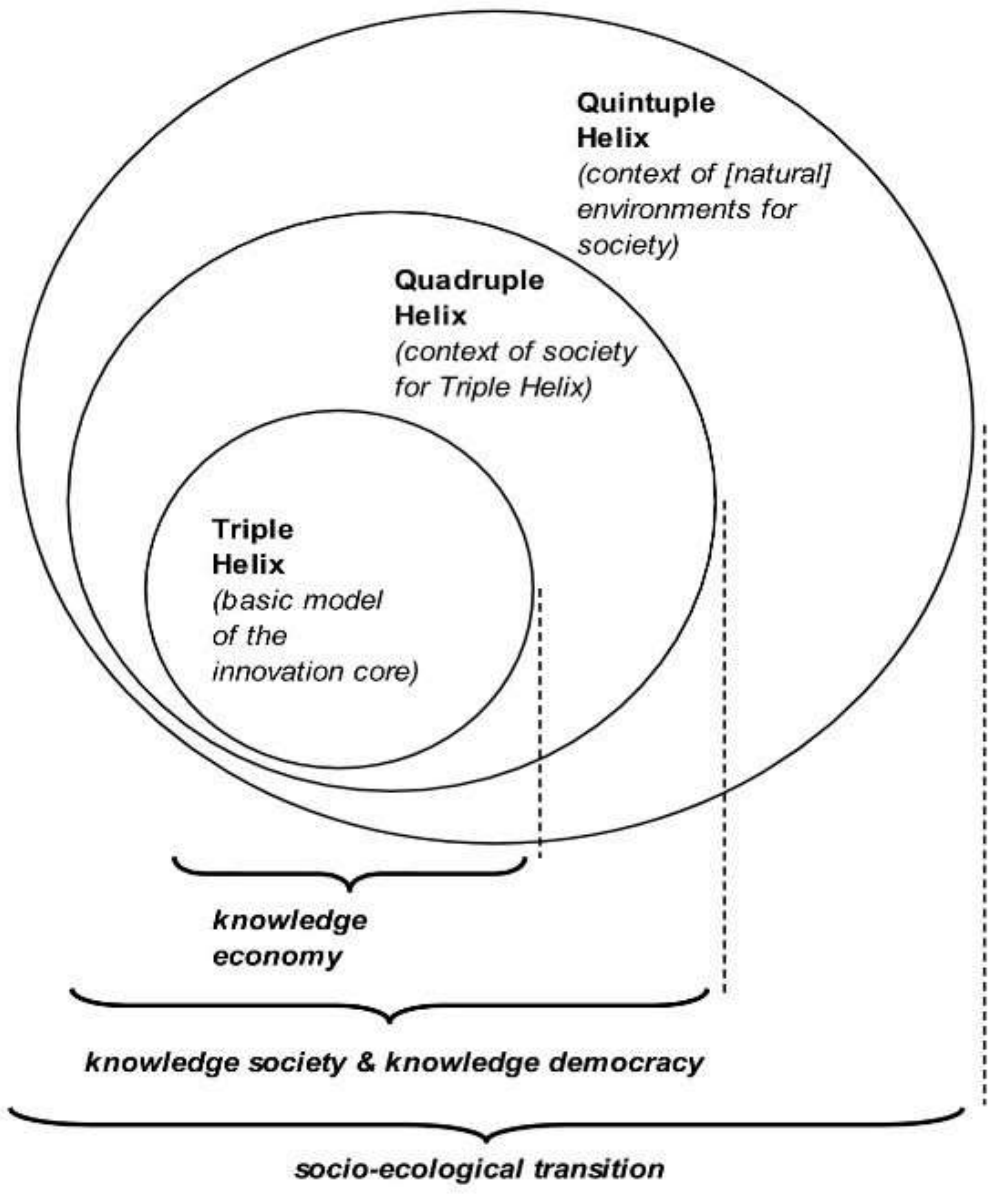



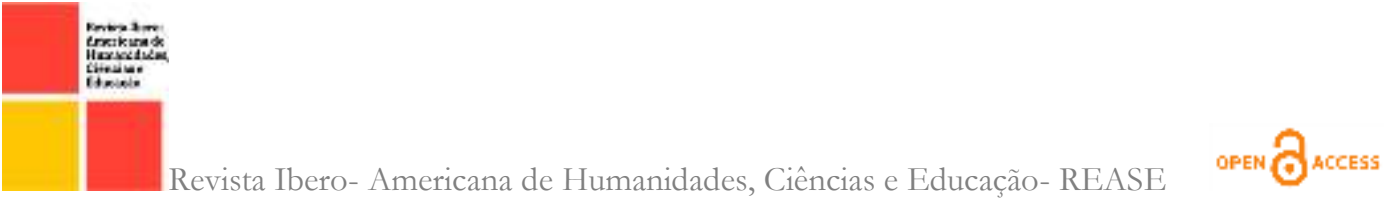

\section{Carayannis et al., 2012.}

Castells \& Himanen (2002) consideram que o desenvolvimento socioeconômico das sociedades pode resultar: da integração de esforços, que envolve empresas/indústrias, os empreendedores/inovadores e as Universidades, a exemplo de Silicon Valley, e de políticas públicas que promovam o desenvolvimento tecnológico, a exemplo do contexto Finlandês.

Em Portugal, por exemplo, um conjunto de mudanças estruturais promoveram reconfigurações na relação Universidade-Sociedade, sobretudo no âmbito empresarial (Pereira \& Pinto, 2012). "Neste contexto a Universidade consolidou rapidamente o estatuto de principal ator na produção de conhecimento científico no panorama nacional. Este papel fulcral, que se aliava à missão central no âmbito do ensino superior, foi alargado ao que tem vindo a ser denominado de Terceira Missão da Universidade” (Pereira \& Pinto, 2012, p. 3).

\subsection{A Terceira Missão da Universidade}

Embora a literatura apresente vários conceitos e definições acerca da Terceira Missão das Universidades, muito tem sido discutido e identificado nesse âmbito.

Para além das tradicionais missões de promover o ensino e a investigação científica, outra incumbência denominada de Terceira Missão passou a integrar as atribuições das Universidades (Koryakina, Sarrico, \& Teixeira, 2015; Montesinos, Carot, Martinez, \& Mora, 2008).

Segundo Pereira e Pinto (2012), esta missão "designa um conjunto de atividades focadas na transferência de conhecimento entre a Universidade e atores externos” (p. 3) e "ainda não está plenamente compreendida e assumida" (p. i4). Para Jongbloed, Enders e Salerno (2008), por consequência, a Terceira Missão consiste essencialmente em transferência de conhecimento, sendo um termo genérico que se refere a uma ampla variedade de princípios orientadores e de estratégias de desenvolvimento socioeconômico.

“Embora não exista uma definição singular acerca da Terceira Missão, ela pode ser definida, de forma geral, como um terceiro papel, além do ensino e da investigação científica, que se centra especificamente sobre a contribuição ao desenvolvimento regional (Jogbloed et al., 2008, citado por Koryakina et al., 2015, p. 63) ou como uma ampla gama de 


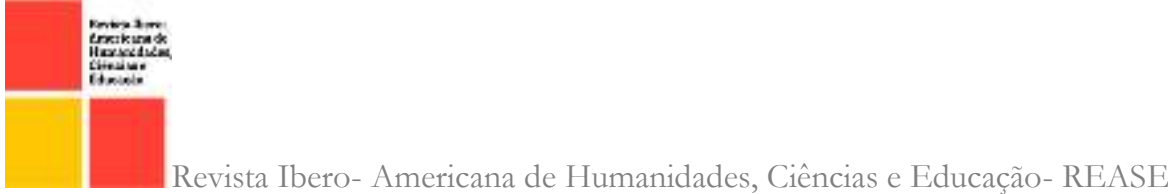

atividades envolvendo a geração, o uso, a aplicação, a exploração e transferência de conhecimentos e de outras capacidades inerentes às academias” (Tuunainen, 2005, citado por Koryakina et al., 2015, p. 63).

Para Montesinos et al. (2008), por conseguinte, as Universidades possuem três missões, complementares, a saber: o ensino, a pesquisa/investigação científica e a transferência de conhecimento para as sociedades, que não só acontece através da consultoria tradicional, da produção de teses, de artigos científicos e de patentes, mas também por meio dos programas de educação continuada, de estágios para os estudantes, de cooperação internacional, das intercorrências e conexões entre as unidades de ensino e de investigação da academia nos parques de ciência e tecnologia, considerados essenciais para fomentar e disseminar a transferência de conhecimento. Contudo, há de se considerar, no escopo da Terceira Missão, as dimensões sociais, empresariais (de fomento ao empreendedorismo) e relacionadas ao ambiente de inovação e desenvolvimento (Montesinos et al., 2008).

Para proceder a uma análise mais ampla da evolução do papel das Universidades, no contexto da Terceira Missão, devem ser considerados dois aspetos marcantes da década de 1990: "a globalização e o imperativo da competitividade" (Caraça, Conceição, \& Heitor, 1996).

Conforme F. S. Santos e Almeida Filho (2012), a internacionalização universitária, consequência de fenômenos contemporâneos, nomeadamente a globalização da economia e da sociedade, a massificação do acesso ao ensino superior e os programas de mobilidade acadêmica, ganha mais e promissor espaço de desenvolvimento. "A internacionalização da prestação de serviços especializados, da transferência de tecnologia, do empreendedorismo, da inovação e da cultura, abre muitas oportunidades para as Universidades e para as empresas" (F. S. Santos \& Almeida Filho, 2012, p. 22).

Para Jongbloed et al. (2008), as Universidades em geral estão sendo forçadas a reconsiderar seus papéis sociais e suas relações com os diversos públicos com os quais se relacionam, os chamados stakeholders, e potenciar as interações com parceiros industriais e regionais. Para as Universidades, a cooperação extramuros configura-se como um forte componente para demonstrar seus aspectos relevantes e captar recursos adicionais 
(Koryakina et al., 2015). Pereira e Pinto (2012) afirmam que, no âmbito da Terceira Missão, as Universidades absorveram atribuições de forma contingencial, muito em função de "pressões exógenas" e para captação de recursos com vistas ao financiamento de projetos.

Segundo Soeiro (2011), a Terceira Missão também está a ser considerada para "refletir as contribuições das Universidades para a sociedade" (p. I) pois "permitem que as instituições, os governos e a indústria possam entender o desempenho das Universidades, adotar e desenvolver práticas recomendadas e assegurar uma contribuição eficaz e eficiente para a sociedade" (Soeiro, 20II, p. 2).

Considerando que muitas Universidades incluem as expressões liderança e empreendedorismo (sendo que estas têm de ser mais do que simples referências para promover o espírito empreendedor, forte liderança e boa governança) em suas declarações de missão, a OECD (2012) elaborou um quadro orientador às Universidades: A Guiding Framework for Entrepreneurial Universities, que apresenta alguns fatores importantes a considerar para a consecução de sucesso nesse aspecto.

Figura 3 - Quadro Orientador Para Universidades Empreendedoras

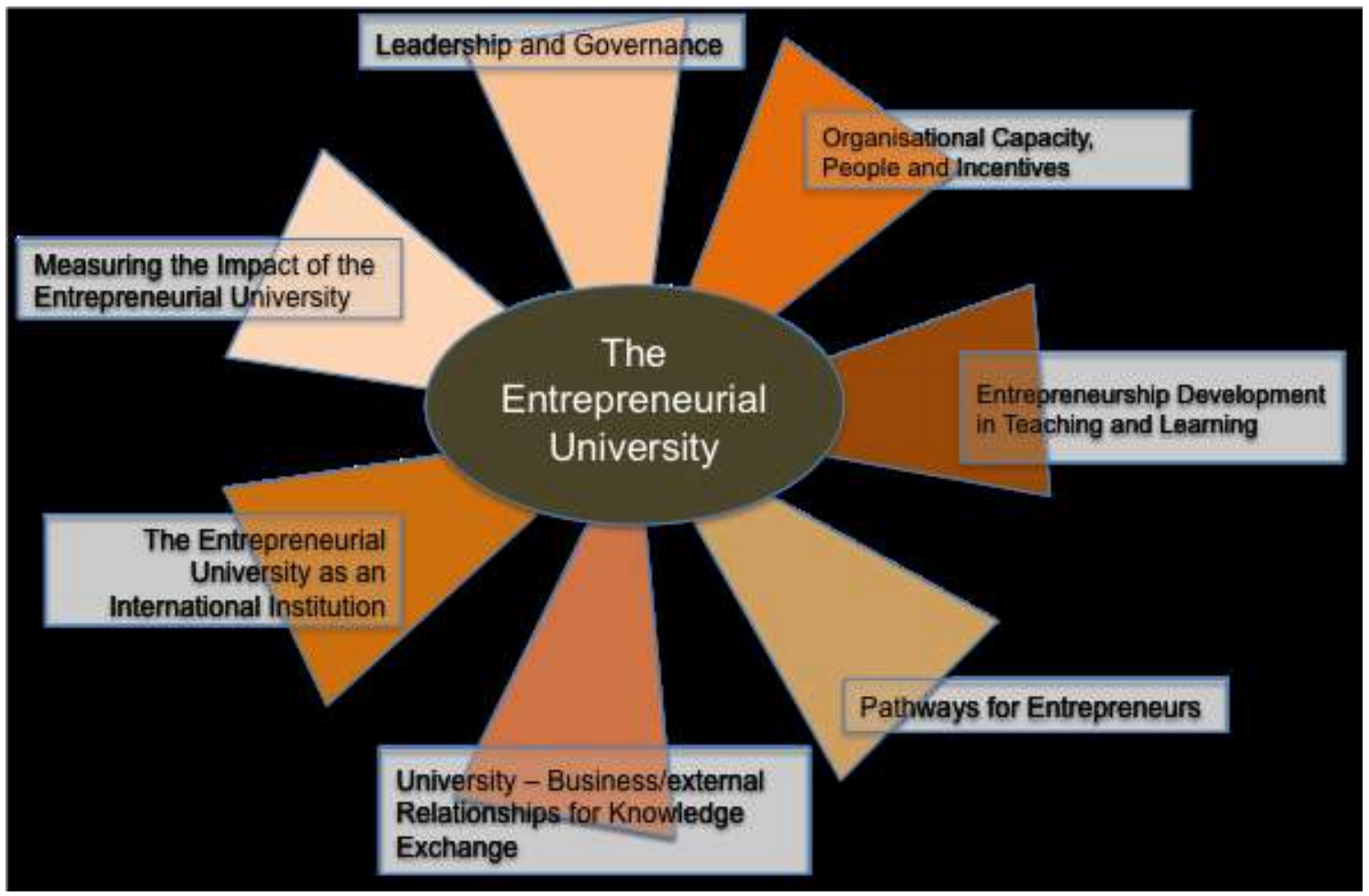

Fonte: OECD, 2012 
Podemos, por conseguinte, depreender que a Terceira Missão tem sido estimulada por uma consciência crescente do papel que as IES podem ou mesmo devem desempenhar, além das missões tradicionais de ensino e de pesquisa/investigação científica (P. N. Teixeira, 2015), designa um conjunto de atividades concentradas nas áreas de Transferência de Tecnologia e Inovação, de Educação Continuada e de "Engajamento Social” (Montesinos, Carot, Martinez, \& Mora, 2008), e promove uma ampla gama de prestação de serviços a diversos indivíduos, grupos sociais, organizações e empresas públicas e privadas, comunidades, sociedade, governo (B. de S. Santos, 1994, 2004, 2008).

\section{METODOLOGIA}

Este estudo é realizado por meio de pesquisa exploratória, na busca de aprofundar os conhecimentos sobre o tema da Extensão Universitária, tratado no artigo como Terceira Missão. Foram utilizados livros, artigos, documentos que propiciassem levantamento bibliográfico e documental sob a ótica da história e da sua aplicação ao longo do tempo. Quanto à coleta de dados, a pesquisa é bibliográfica e documental.

\section{CONSIDERAÇÕES FINAIS}

As Instituições de Ensino Superior (IES), no contexto das atividades associadas à Terceira Missão, podem desempenhar papéis importantes para o desenvolvimento socioeconômico dos territórios. Além disto, as realizações que contribuam efetivamente, pela natureza translativa dos projetos pertinentes, tornam-se um referencial positivo de avaliação pública - o patrimônio mais importante da Universidade - favoreçam os processos de formulação e implementação de políticas públicas e, de forma inovadora, lançam luz sobre um tema transversal àqueles abordados neste artigo, qual seja: ESG Environmental, Social and Corporate Governance.

A criação de núcleos ou unidades de $I d D+i$ (Investigação, Desenvolvimento e Inovação), que interliguem as agências públicas de desenvolvimento, empresas e institutos de ensino e pesquisa na ação coletiva, a identificação de Instituições de Ensino Superior e de outras organizações para integrar uma rede de think thank internacional em inovação e a 

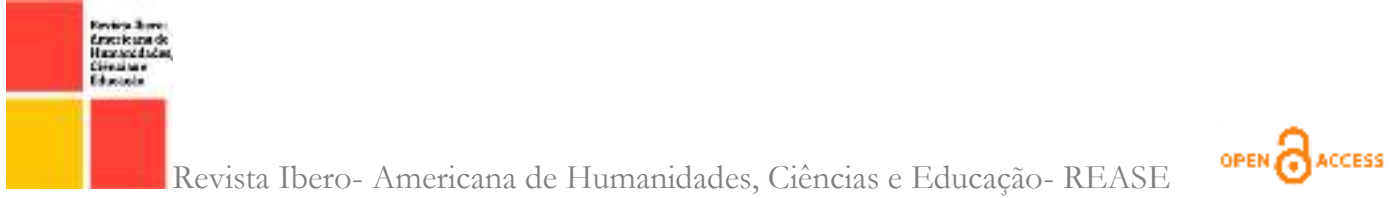

criação de living labs internacionais são iniciativas a considerar no plano estratégico de internacionalização.

É importante destacar que os projetos resultantes destas associações podem contribuir também para a formulação e implementação de políticas públicas. As redes epistêmicas ou networks of knowledge-based experts, constituídas essencialmente por profissionais com expertises e competências reconhecidas em domínios ou assuntos específicos e que, num contexto geral, atuam junto a Estados para produzir políticas públicas, devem também ser compreendidas/consideradas nesta dimensão.

É aconselhável também avaliar a oferta formativa contemporizando-a aos contextos nacional e internacional, designadamente a criação de novos cursos ou formações que possam dar resposta às necessidades do mercado e assegurar padrões adequados de formação contínua, devidamente articulados com as inovações tecnológicas. O relatório “Empregos do Futuro”, apresentado no Fórum Econômico Mundial de Davos, assinala as carreiras que deverão surgir em diversas áreas e estão organizadas em sete grupos principais, a saber: Care Economy, Data and AI, Engineering and Cloud Computing, Green Economy, People and Culture, Product Development, Sales, Marketing and Content.

De referir que, no Brasil, as IES públicas estão a passar por constrangimentos orçamentários que provocam uma dissonância entre as exigências de eficácia nos resultados e de eficiência nos processos de administração dos recursos financeiros e organização interna. Como se não bastasse, até os recursos para investigação científica são desviados. Recentemente, por exemplo, no dia 2I de setembro de 2021, a Polícia Federal do Brasil deflagrou a Operação Klopês, com o objetivo de apurar esquema de desvio de recursos de projetos de pesquisa financiados pela Fundação de Empreendimentos Científicos e Tecnológicos (Finatec), vinculada à Universidade de Brasília (UnB), e pelo Conselho Nacional de Desenvolvimento Científico e Tecnológico (CNPq).

De outro lado, as IES particulares, tanto as "faculdades isoladas" quanto as grandes players do mercado, têm um desafio mais premente, contundente e "precedente": assegurar os posicionamentos mercadológicos e a sobrevivência, designadamente através da captação e retenção de alunos. O cenário não é alentador, sobretudo quando observamos os números da evasão escolar no contexto da Educação Básica e os constrangimentos 
causados pelo decréscimo de políticas de financiamento governamental aos estudantes para ingresso no ensino superior.

Ressalte-se que estas condicionantes já causam um atraso abismal no que tange ao tema central deste artigo, afora, obviamente, as vocações e missões que permeiam as orientações estratégicas das IES. Enquanto isso, inevitavelmente, respostas concretas ao desenvolvimento socioeconômico ficam relevadas e afetam, sobremaneira, os índices sociais, notadamente o de desenvolvimento humano e bem-estar social.

Por conseguinte, apesar da resposta à questão principal deste artigo ser afirmativa, conforme destacado no primeiro parágrafo desta seção, surgem outras perguntas, designadamente: A natureza jurídica das IES influencia o desenvolvimento das atividades no âmbito da Terceira Missão? A implantação de IES constitui um marco importante no desenvolvimento socioeconômico dos territórios? As IES funcionam como um mecanismo indutor de desenvolvimento local e regional? É viável para as IES colaborarem com os governos locais, promoverem sinergia entre os diversos atores regionais e auxiliarem na formulação e implementação de políticas públicas? Como é que os docentes e pesquisadores/investigadores percebem a influência do estatuto jurídico da instituição nas atividades que desenvolvem associadas à Terceira Missão?

\section{REFERÊNCIAS BIBLIOGRÁFICAS}

Altbach, P. G. Higher education and the WTO: Globalization run amok. International Higher Education, 23(Spring), 2-4, 2001

Amaral, A., \& Magalhães, A. The Triple Crisis of the University and its Reinvention. Higher Education Policy, I6(2), 239-253. http://doi.org/Io.1057/palgrave.hep.8300018, 2003

Buarque, C. A Universidade Numa Encruzilhada. In E. Appel (Ed.), A Universidade NUma Encruzilhada: Seminário Universidade: por que e como reformar? (pp. 23-65). Brasília, Brasil: Edições Unesco Brasi. Retrieved from http://unesdoc.unesco.org/images/oor3/oor339/133968POR.pdf, 2003

Caraça, J. M. G., Conceição, P., \& Heitor, M. V. Uma Perspectiva sobre a Missão das Universidades. Analise Social, 31(139), I2OI-I233. Retrieved from http://analisesocial.ics.ul.pt/, 1996

Carayannis, E. G., Barth, T. D., \& Campbell, D. F. The Quintuple Helix innovation model: global warming as a challenge and driver for innovation. Journal of Innovation and Entrepreneurship, 12. http://doi.org/10.1186/2192-5372-1-2, 2012 


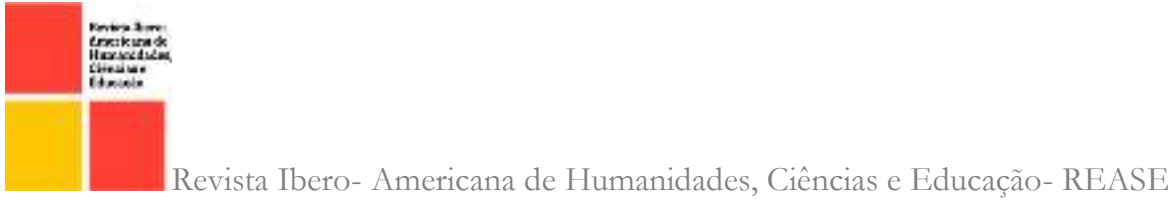

Castells, M., \& Himanen, P. The information society and the welfare state: The Finnish model. New York. Retrieved from https://books.google.pt, 2002

Clotet, J. Apresentação. In J. L. N. Audy \& M. C. Marosini (Eds.), Inovacão, Universidade e relação com a socieadade (pp. Io-II). Retrieved from http://www.pucrs.br/edipucrs/inovacao.pdf, 2009

Clrark, G. L., Feldman, M. P., \& Gertler, M. S. The Oxford Handbook of Economic Geography. Oxford: Oxford University Press. Retrieved from https://books.google.pt, 2000

Drucker, P. Inovação e Gestão: uma nova concepção de estratégia de empresa (3rd ed.) Lisboa: Presença, 1989

Fernandes, J. M. S. R. O impacto económico das instituições de ensino superior no desenvolvimento regional: o caso do Instituto Politécnico de Bragança. Instituto Politécnico de Bragança. $\quad$ Retrieved from http://repositorium.sdum.uminho.pt/bitstream/r822/10535/I/TESE_DOUTORAMENT O_JOANA_FERNANDES.pdf, 2009

Jongbloed, B., Enders, J., \& Salerno, C. Higher education and its communities: Interconnections, interdependencies and a research agenda. Higher Education, 56(3), 303324. http://doi.org/10.1007/s10734-008-9128-2, 2008

Knight, K. E. A Descriptive Model of the Intra-Firm Innovation Process. The Journal of Business, 4o(4), 478-496. Retrieved from http://www.jstor.org/stable/2351630, 1967

Koryakina, T., Sarrico, C. S., \& Teixeira, P. N. Universities' Third Mission Activities. In E. Reale \& E. Primeri (Eds.), The Transformation of University Institutional and Organizational Boundaries (pp. 63-82). SensePublishers. http://doi.org/1o.1007/978-946300-178-6_4, 2015

Lee, H. B. An Application of Innovation Theory to Strategy of Administrative Reform in Developing Countries. Policy Sciences, I(2), I77-I89. http://doi.org/Doi 10.1007/Bfool45204, 1970

Lundvall, B.- $\AA$., \& Borrás, S. The globalising Learning Economy: Implications for Innovation Policy. European Commission, Luxembourg, (December). Retrieved from https://scholar.google.pt, 1997

Mano, M., \& Marques, M. da C. da C. Novos modelos de governo na Universidade pública em Portugal e competitividade. Revista de Administração Pública, 46(3), 721-736. http://doi.org/10.1590/So034-76122012000300005, 2012

Montesinos, P., Carot, J. M., Martinez, J., \& Mora, F. Third mission ranking for world class universities: Beyond teaching and research. Higher Education in Europe, 33(2-3), 259-271. http://doi.org/10.1080/03797720802254072, 2008 
OECD. Manual de Oslo: Diretrizes para a Coleta e Interpretação de dados sobre Inovação. OCDE, Eurostat e Financiadora de Estudos e Projetos. FINEP. Retrieved from http://www.finep.gov.br/, 1997

OECD. A Guiding Framework for Entrepreneurial Universities. OECD \& European Commission. Retrieved from https://www.oecd.org, 2012

Oliveira, J. M. F. C. de. Gestão da Inovação. (Sociedade Portuguesa de Inovação, Ed.) (Ist ed.). Porto: Principia Publicações Universitárias e Científicas, 1999

Pedrosa, J., Santos, H. C., Mano, M., \& Gaspar, T. Novo Modelo de Governança e Gestão Das Instituições de Ensino Superior em Portugal: Análise dos Usos do Modelo em Instituições Públicas. In Autonomia e Governança das Instituições Públicas de Ensino Superior (p. 159). Aveiro, Portugal. Retrieved from http://www.cnedu.pt/pt/noticias/cne/49-estudo-cne-sobre-o-rjies, 2012

Pereira, T. S., \& Pinto, H. Institucionalização da Transferência de Conhecimento: Políticas Públicas e Formação De Actores-Rede na Universidade Portuguesa. In VII Congresso Português de Sociologia. Sociedade, Crise e Reconfigurações (p. 16). Porto. Retrieved from http://www.aps.pt/vii_congresso/papers/finais/PAPı26o_ed.pd, 2012

Santos, B. de S. Pela Mão de Alice. O Social e o Político na Pós-Modernidade. Porto: Edições Afrontamento, 1994

Santos, B. de S. A Universidade no Século XXI: Para uma reforma democrática e emancipatória da Universidade. Cortez. Retrieved from 1031 http://www.ces.uc.pt/bss/documentos/aUniversidadedosecXXI.pdf, 2004

Santos, B. de S. A Universidade no Século XXI: Para uma Universidade Nova. Retrieved March 27, 2016, from http://hdl.handle.net/10316/12122, 2008

Santos, F. S., \& Almeida Filho, N. de. A Quarta Missão da Universidade: Internacionalização Universitária na Sociedade do Conhecimento. Imprensa da Universidade de Coimbra; Editora da Universidade de Brasileira. http://doi.org/http://dx.doi.org/Io.14195/978-989-26-0573-9, 2012

Santos, A. B. A. dos, Faizon, C. B., \& Meroe, G. P. S. de. Inovação: Um Estudo Sobre a Evolução Do Conceito De Schumpeter. Caderno de Adimistração, 5, I-I6. Retrieved from http://revistas.pucsp.br/index.php/caadm/article/view/90I4/6623, 20II

Śledzik, K. Schumpeter's View on Innovation and Entrepreneurship. Management Trends in Theory and Practice, 89-95. http://doi.org/http://dx.doi.org/10.2139/ssrn.2257783, 2013

Soeiro, A. A terceira missão das Universidades: indicadores. In Congresso FEUP 201 . Porto. Retrieved from http://hdl.handle.net/10216/56755, 201I

Solo, C. S. Innovation in the Capitalist Process: A Critique of the Schumpeterian Theory. The Quarterly Journal of Economics, 65(3), 417-428. Retrieved from http://www.jstor.org/stable/r882222, 195I 
Sotarauta, M. Strategy Development in Learning Cities. Tampere, Finlândia. Retrieved from http://www.uta.fi/haku.php, 2004

Teixeira, A. A Universidade de Ontem e de Hoje. Retrieved March 23, 2016, from http://www.bvanisioteixeira.ufba.br/artigos/ontem.html, i964

Teixeira, P. N. Extensão Universitária na Europa: A Terceira Missão. In Revista Brasileira de Extensão Universitária (Vol. 6, pp. 59-62), 2015

Ven, A. H. Van de. Central Problems in the Management of Innovation. Management Science, 32(5), 590-607. Retrieved from http://www.jstor.org/stable/2631848, 1986 